\title{
Discussion
}

\section{The transition of the European Proteomics Association into the future}

\author{
Garry L. Corthals, ${ }^{a, *}$, Mike Dunn $^{b}$, Peter James ${ }^{c}$, Concha Gil ${ }^{d}$, Deborah Penque $e^{e}$, \\ Juan Pablo Albar ${ }^{f}$, Per Andrén ${ }^{g}$, Thierry Rabilloud ${ }^{h}$, György Marko-Varga ${ }^{i, j}$ \\ ${ }^{a}$ Turku Centre for Biotechnology, University of Turku and Åbo Akademi University, Turku, Finland \\ ${ }^{\mathrm{b}}$ Proteome Research Centre, Conway Institute of Biomolecular and Biomedical Research, University College Dublin, Ireland \\ ${ }^{\mathrm{c}}$ Department of Protein Technology, Lund University, Sweden \\ ${ }^{\mathrm{d}}$ Dept. Microbiology Ii \& Proteomics Unit, Faculty of Pharmacy, Complutense University, Madrid, Spain \\ ${ }^{\text {e }}$ Laboratório de Proteómica, Depatamento de Genética, Instituto Nacinal de Saúde Dr Ricard Jorge, Lisbon, Portugal \\ ${ }^{\mathrm{f}}$ ProteoRed, National Center for Biotechnology-CSIC, Madrid, Spain \\ gDepartment of Pharmaceutical Biosciences, Medical Mass Spectrometry, Uppsala University, Biomedical Centre Box 591, \\ SE-75124 Uppsala, Sweden \\ ${ }^{\mathrm{h}}$ Laboratoire de Bioenergetique Cellulaire et Pathologique, Grenoble, France \\ ${ }^{i}$ Div. Clinical Protein Science \& Imaging, Biomedical Center, Dept. of Measurement Technology and Industrial Electrical Engineering, \\ Lund University, Sweden \\ ${ }^{j}$ Dept. Of Surgery, Tokyo Medical University, Tokyo, Japan
}

\section{A R T I C L E I N F O}

Keywords:

EuPA

Proteomics

\begin{abstract}
A B S T R A C T
The following report provides an overview of the discussions and outcome of the EuPA General Council meeting that took place in Estoril 20-21 October 2010. During the annual meeting future policy and action plans in a variety of areas are decided. Several important points were decided upon during this meeting including the expansion of the EuPA Executive Committee by introducing a new EuPA committee - EuPA Developments - that will initially spearhead activities in standardisation, imaging $\mathrm{ms}$ and biobanking. The EuPA General Council also invited Russia as its 17th member. More details about these and additional activities are presented in the article.
\end{abstract}

(c) 2011 Published by Elsevier B.V.

\section{Expanding EuPA's activities and increasing proficiency}

\subsection{A foreword on EuPA}

The representatives of the 17 European national proteomics societies met up in Estoril at the 7th Meeting of the General Council of the European Proteomics Association (EuPA).
Since its inception 7 years ago EuPA has established itself as a leading regional organisational body advancing directions and interests of the 17 independent countries it represents. The General Council, where each society is equally represented, is EuPA's governing body. During the General Council meetings important directions and decisions for Eu-proteomics are debated, voted upon and ratified.

Since its inception EuPA has grown. Initially, the regional aspect and its organisational structure and operations led to

\footnotetext{
* Corresponding author. Tel./fax: +358 23338889.

E-mail address: garry.corthals@btk.fi (G.L. Corthals).
}

1874-3919/\$ - see front matter @ 2011 Published by Elsevier B.V. doi:10.1016/j.jprot.2011.06.018 
the wider recognition of EuPA. This in turn has led to expanded input, further developments and increased membership participation over the years. More recently EuPA has become involved as the regional coordinating body of various Eu-wide activities, impacting on many scientific careers and developments. Thus, the gathering and operation of the EuPA's General Council has an impact on European science at large. Other organisations such as the European Commission and professional international bodies such as HUPO have now also recognised EuPA. Through the membership of the constituent national societies, the EuPA represents several thousand proteomic scientists working in Europe, as well as visiting scientists from all over the world working in Europe. Therefore, decisions made by the General Council effect future developments and directions. Because of this, it has become an important and exciting activity to gather, discuss and decide points that have the potential to advance proteomics regionally.

\subsection{Estoril milestones}

One of the important points on the agenda for the Estoril meeting focussed on a new structure and activities of the Executive Committee. The members of the Executive Committee of EuPA had proposed that to move EuPA forward, timely and reinvigorated policies and strategies were required to maintain a positive impact on proteomics in Europe. The following points are main outcomes of the General Council meeting:

A. The General Council elected Jean-Charles Sanchez as the next EuPA Vice President, and György Marko-Varga as the next EuPA President. The General Council also decided on the launch of a new fifth committee EuPA Developments that now comprises three new sections (more below). The leaders of each section will be responsible to develop these new initiatives and invite members into the respective sections. The new structure of the EuPA is depicted in Fig. 1.

B. The central role and key future function of the funding committee was also discussed. The Executive Committee presented a plan where the future of the funding committee plays a central role, due to the increase in EuPA activities. Therefore, the funding committee will soon require more resources and attention. To meet these tasks, David O'Connor, Marius Ueffing and Peter Verhaert were elected as new members within the Funding Committee.

C. The EuPA General Council also invited Russia as its 17th member. Alexander Archakov, the president of the Russian Human Proteome Organization (RHUPO) gave a presentation of the Russian Proteomics organisation and activities. Details about their activities can be found via our web site.

- EuPA is forming its strategic future directives where the key considerations in building this strategy were defined. The salient points emerging from the discussions were that i) EuPA supports its national proteomics societies in the best way, and ii) the strategy should position EuPA where it plays a key global role in regional and global proteomics initiatives.

\section{Activities of EuPA's committee in 2009/10}

\subsection{The EuPA/HUPO committee}

The liaison committee between EuPA and HUPO has played its triple role, i.e. i) transferring information from HUPO to EuPA as smoothly and as fast as possible, ii) trying to push forward

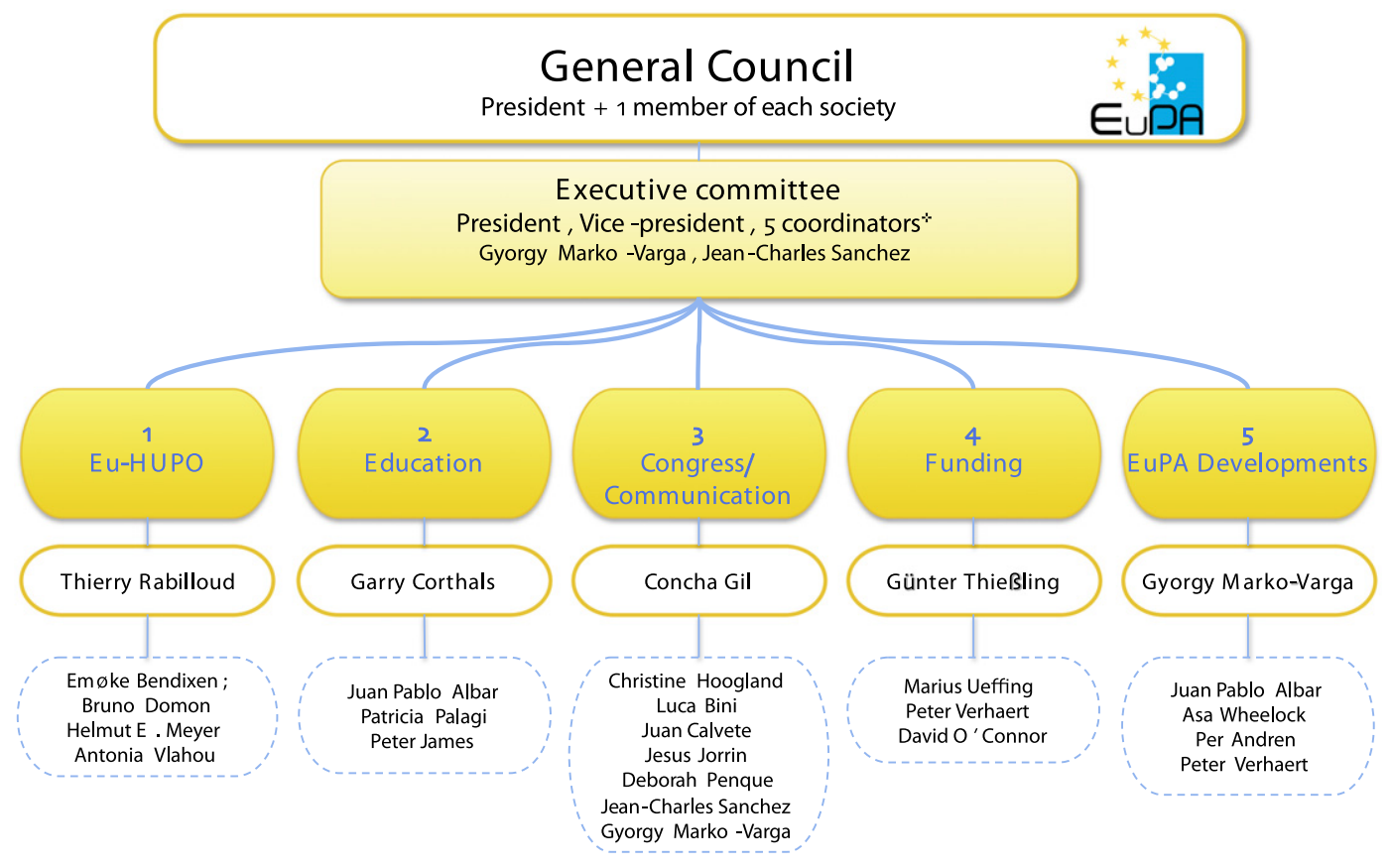

Fig. 1 - The new EuPA structure: five committees with the respective members of each committee. 
EuPA's view into HUPO vision and operating rules and iii) when available, coordinating HUPO and EuPA actions.

The most important actions have taken place in the latter two aspects. One example is the tutorial programme, for which the EuPA/HUPO committee has coordinated interests between EuPA and HUPO, and to foster an active participation of the major proteomics journals, including Journal of Proteomics. The programme is now under way and the first tutorial papers should appear in 2011.

There are two other examples worth mentioning. The first one is the gradual opening of HUPO to non-human, nonmammalian proteomics, something that EuPA has promoted since its beginning. The second example is the representation of the regional proteomic societies (including EuPA of course) in the HUPO board of directors, via directors nominated directly by each regional society. This latter action is not implemented yet, but should be implemented in 2012 .

Thus, the EuPA/HUPO committee is happy to note that both EuPA as a body and its ideas and vision are better taken into account in HUPO's vision and operations.

\subsection{EUPA CCC}

The Congress and Communication committee has been engaged in a successful launch of the EuPA Newsletter. So far four issues have been published, where the members of the 17 national societies, and others, can follow the events and progresses made as well as future planning of the activities (www.EuPA.org). The last issue of the EuPA bulletin has just been released. It contains the message from the President and EuPA latest news, information from the Russian proteome society, meeting reports, information from the Journal of Proteomics, and other information from the proteomics world. The fifth issue is under construction and will be published shortly.

The oral and poster presentations of the 3rd EuPA Congress (2009) were published as short manuscripts [1], and are also posted in the EuPA database that can be accessed from the EuPA homepage (www.EuPA.org). In addition, a special issue of the Journal of Proteomics came out early in 2010 [2] with manuscripts from the EuPA Congress in Stockholm. The short papers from the 4th EuPA Congress in Estoril recently, were also published as a proceedings issue [3] in 2010, and a call for a special issue in 2011 is under development. Papers for the Estoril EuPA Congress will be found in this journal during the course of 2011.

\subsubsection{EUPA and HUPO/EuPA congresses}

The CCC has an elaborate document concerning the "Rights and duties for the endorsement of the EuPA Annual Scientific Meeting". This document is the basis for the selection of national proteomics society candidates. In Estoril the EuPA General Council made decisions for the venues for the St. Malo EuPA 2013 Congress, France, and the Madrid HUPO/EuPA 2014 Congress, Spain (Fig. 2). The past and the forthcoming EuPA congresses are presented in Table 1.

The HUPO-EuPA Congress in Geneva, 2011 will hold a workshop on non-human oriented proteomics research that will take place, September 4th, 2011. The main topics will be plant, animal and microorganism proteomics. EuPA will provide up to 40 bursaries for students in a $50 \%$ reduction of
Table 1-The EuPA annual congresses: joint HUPO congresses are scheduled every 3 years.

\begin{tabular}{lll} 
Year & \multicolumn{1}{c}{ Location } & Organisations \\
\hline 2007 & Valencia, Spain & EuPA \\
2008 & Amsterdam & HUPO/EuPA \\
2009 & Stockholm, Sweden & EuPA \\
2010 & Estoril, Portugal & EuPA \\
2011 & Geneva, Switzerland & HUPO/EuPA \\
2012 & Glasgow, Scotland & EuPA \\
2013 & St. Malo, France & EuPA \\
2014 & Madrid, Spain & HUPO/EuPA \\
\hline
\end{tabular}

the fee. In addition a presentation on EuPA's achievements and plans will be organised.

\subsection{EuPA education - Europe's knowledge network}

A well-documented list of courses and activities has been established in recent years. For a complete list of these activities we invite the reader to view the events and material listed on the EuPA website. Further information about the strategic development of educational plans is listed below.

The Education Committee has established a wide range of activities that comprises basic courses, advanced courses, support for summer and winter schools, workshops, education days at EuPA meetings, the tutorial programme (in collaboration with HUPO), and there is teaching material that is publicly available from the EuPA website. The collected activities of the Education Committee have elevated EuPA to a position where it has become more than a network of scientists. These enhanced activities are leading us towards becoming a pan-European knowledge network. Indeed these are exciting developments, and they are critically dependent on the resources sustained over time, so that material is updated, and knowledge dissemination reaches out to all corners and scientists in need.

In the near future EuPA will release call for funding to support a variety of high quality courses and summer/winter schools in proteomics. There are four basic courses for which teaching material exists and may be used: gel-based proteomics, MS-based proteomics, chromatography-based proteomics, and bioinformatics for proteomics. Plans for new courses that cover proteomics-basics not already listed will be welcomed. For the advanced courses our objective is to disseminate expertise in technically advanced or novel methods and emerging techniques to a broad number of laboratories. The primary objective is to ensure that participants can implement newly learned methods and techniques in their own laboratories. A new activity we will establish is the EuPA sponsored summer and winter schools, which aim to provide an international forum for the presentation and discussion of frontier research in all aspects of proteome sciences. For more information about these exciting activities please visit the EuPA website.

One way to improve education is through the provision of high quality peer-reviewed teaching material. To this end, the International Proteomics Tutorial Programme has been launched (http://www.proteomicstutorials.org). It is a cooperation between the four main journals that publish in the field of proteomics on the one hand, and HUPO. EuPA 
and their affiliated regional and national organisations. The programme is being organised by Peter James, Kazuyuki Nakamura and Thierry Rabilloud. A set of 48 tutorial articles accompanied by a PowerPoint lecture are being commissioned and the series will be launched in the summer of 2011.

\subsection{EuPA developments}

The new EuPA committee, "New Developments" was introduced in Estoril by the Executive Council and approved by the General Council. The aim of this new committee is to promote emerging research areas and activities that will be important in the near future and that will give EuPA as an organisation an operational role, based upon the activities within the three respective sections. Three sections selected for current development are standardisation, imaging mass spectrometry and biobanking which will be briefly discussed below.

\subsubsection{Standardisation}

Mass spectrometry (MS) based proteomics has evolved substantially over the past decade and a new scenario can be visualised with major improvements in instrumentation, novel (targeted) methodologies, comprehensive sequence database, automation and reports with identification and quantifications of thousands of proteins. In particular the speed and content, automation of scoring and subsequent reporting require robust quality control (QC) and standardisation approaches to attain appropriate reliability of the technology applied.

ABRF, HUPO and ProteoRed [1-5] have developed test standards to evaluate end-to-end quality control for proteomics. A detailed effort towards systematic QC has been undertaken by the National Cancer Institute (NCI) via its large-scale Clinical Proteomic Technology Assessment for Cancer (CPTAC) project [6,7]. Clearly these efforts underscore the importance of excellence in proteomics standards and by virtue of their findings have defined actions for improving the quality of data and evaluating the robustness, repeatability and reproducibility of defined proteomics workflows [8]. A ProteoRed proposal for 2011 exists for targeted quantitative proteomics study where SRM, pseudo SRM and not targeted approaches will be evaluated. Details for taking part in this study (called PME-7) can be obtained from www.proteored.org and www.EuPA.org.

\subsubsection{Imaging mass spectrometry}

It is the objective of the EuPA imaging mass spectrometry group to align and collaborate with already existing expert groups, such as the European imaging mass spectrometry consortium. As the imaging mass spectrometry field is a multidisciplinary research field it bridges scientists from the mass spectrometry field with pathologists, biologists, chemists, biostatisticians and bioinformation.

The mission and goals of this new section will be to collaborate, share expert experience, as well as to give workshops and tutorials. In more detail, the aim is to disseminate methods, develop synergies between its members, develop standardised methods and tools, test applicability, capacities and limitations for a variety of different diseases, provide resources, training and guidelines, and to establish imaging mass spectrometry amongst a broader scientific community. The aim is to build and strengthen synergies between the connections already developed within European imaging mass spectrometry research laboratories.

\subsubsection{Biobanking}

TIME magazine highlighted biobanking as one of "10 Ideas Changing the World Right Now". Biobanking is rapidly growing and thriving to change approaches to target finding,

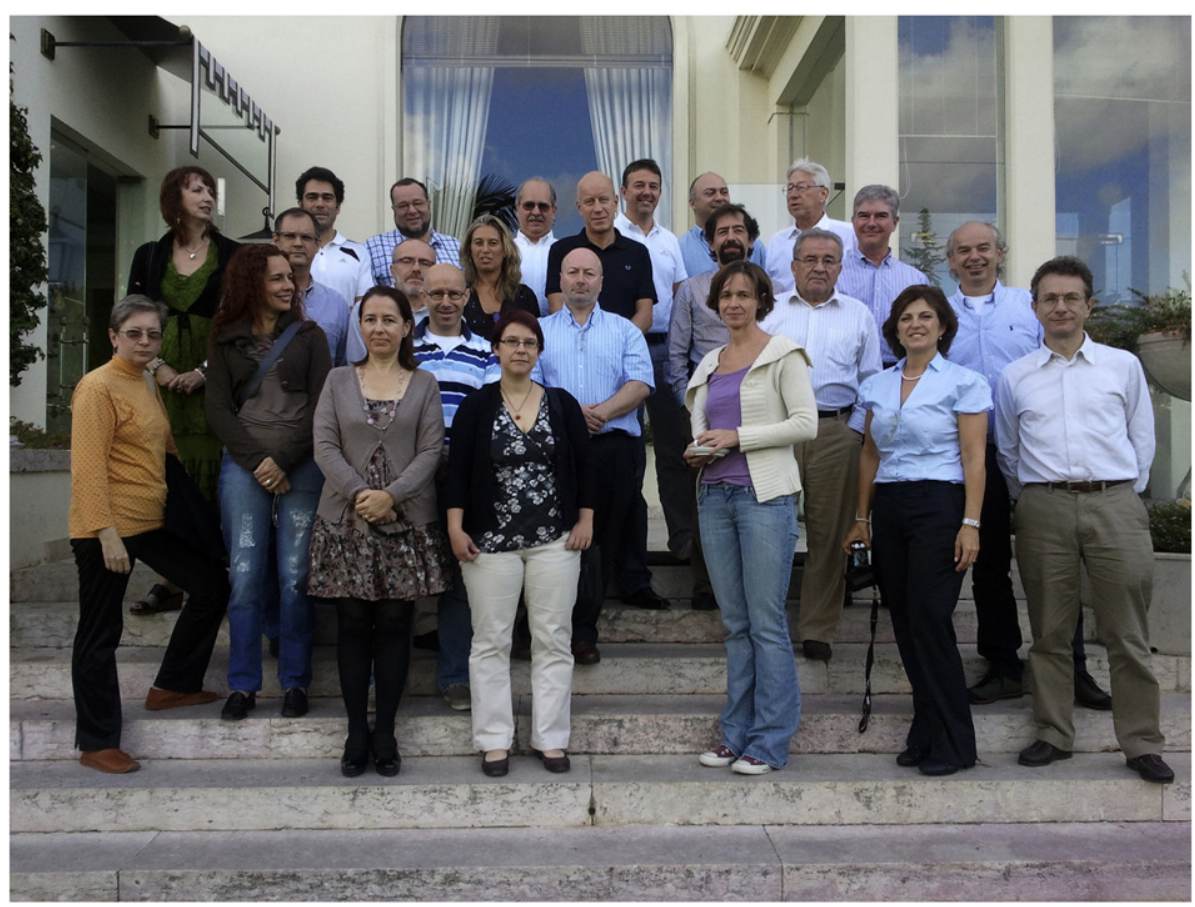

Fig. 2 - Photograph of the EuPA General Council members and participants at the 4th EuPA Scientific Meeting that took place in Estoril, Portugal, 2011. 
drug development and patient treatment. It is being viewed as a key driver for the next generation biomarker and drug discovery, including developments within biobank initiatives that are quickly increasing globally. Another area is the health care area that is in great need for early diagnosis. Biobanks that hold archived clinical material are to be used for the discovery of biomarkers for disease grading and indications, along with epidemiological studies.

\section{In conclusion}

Most importantly there will be significant time set aside to discuss in some detail how we can shape EuPA's future over the next period to maximise its influence and visibility at the European and world-wide level. A new Operating Committee of the Executive Committee, Chaired by György Marko-Varga, has been formed to take these initiatives forward. As EuPA develops its activities, where research driven projects has been assigned, such as the three in "New Developments", we will be looking at expanding our achievements and deliveries. Many of these are expected to be published and presented in the Journal of Proteomics, which is the EuPA proteomics research journal.

\section{R E F E R E N C E S}

[1] Albar JP, Corthals GL, Gil C, James P, Jensen ON, Palagi PM, et al. Promoting proteomics knowledge in Europe: report on the activities of the EuPA Education Committee 2006-2007. Proteomics 2007;7(Suppl 1):90-4.

[2] James P, Corthals G, Gil C. Proteomics education, an important challenge for the scientific community: report on the activities of the EuPA Education Committee. Proteomics 2006;6(Suppl 2): 77-81.

[3] Paradela Alberto, Escuredo Pedro-Ramón, Albar Juan-Pablo. Proteomics initiatives in Spain: ProteoRed proteomics 2006;6 (No S2):73-6.

[4] Marko-Varga G, Simões T, editors. Proceedings of the 4th EuPA scientific meeting: a proteomics odyssey towards next decades, Estoril, Portugal, October 23-27 2010. H-8200 Veszprem, Hungary: Ook Press; 2010.

[5] Marko-Varga G, Laurell T. J Proteomics 2010;73:1043-4.

[6] Friedman DB, et al. The ABRF Proteomics Research Group studies: educational exercises for qualitative and quantitative proteomic analyses. Proteomics 2011;11:1371-81.

[7] Bell AW, et al. A HUPO test sample study reveals common problems in mass spectrometry-based proteomics. Nat Methods 2009;6:423-30.

[8] Martinez-Bartolome S, Blanco F, Albar JP. Relevance of proteomics standards for the ProteoRed Spanish organization. J Proteomics 2010;73:1061-6. 